\title{
Antibacterial potential of strawberries and basil extract combination against Streptococcus sanguinis (ATCC 10556)
}

\author{
Hendra Dian Adhita Dharsono1, Denny Nurdin'1, Fajar Fatriadi', Yolanda Dwiutami \\ Gondowidjojo ${ }^{2}$, Ellizabeth Yunita ${ }^{1}$, Eti Apriyanti ${ }^{3}$
}

\begin{abstract}
${ }^{1}$ Department of Conservative Dentistry, Faculty of Dentistry Universitas Padjadjaran, Indonesia 2Department of Restorative Dentistry, Faculty of Dentistry Lincoln University College, Malaysia ${ }^{3}$ Department of Chemistry, Faculty of Mathematics and Natural Science Universitas Padjadjaran, Indonesia
\end{abstract}

\begin{abstract}
Introduction: Streptococcus sanguinis is a commensal microorganism as well as a pioneer colony in forming dental plaque. Oral biofilm formation can be prevented by a mechanical cleaning procedure followed by the use of mouthwash. The current gold standard for mouthwash is chlorhexidine. Nevertheless, it has side effects that are not recommended for long-term use. Previous studies had proven that herbal-based mouthwashes such as basil leaves (Ocimum basilicum) and strawberry fruit (Fragaria $x$ ananassa) have been shown to have antibacterial properties. The effectivity of antibacterial activity phenomenon in combined extracts has been reported in other studies. This research aims to observe the antibacterial potential of the $F . x$ ananassa and $O$. basilicum extract combinations against S. sanguinis (ATCC 10556). Methods: The sample of this study was a combination of $F . x$ ananassa and 0 . basilicum extract, which initially screened for their antibacterial activities. Antibacterial activities of $F . x$ ananassa and $O$. basilicum extracts against S. sanguinis were observed using Kirby Bauer method, while Minimum Inhibitory concentration (MIC) and minimum bactericidal concentration (MBC) by serial microdilution method. The $2 \%$ concentration from each extract was combined in 1:1, 1:2, and 2:1 volume ratio variations then tested for inhibitory zones, MIC, and MBC. Results: F. $x$ ananassa extract had $0.125 \%$ and $0.25 \%$ for MIC and $M B C$ respectively, while $O$. basilicum extract showed the value of MIC and MBC as $0.031 \%$ and $0.063 \%$ against $S$. sanguinis (ATCC 10556). The extract combinations in 1:1, 1:2, and 2:1 volume ratio variations showed $0.016 \%$ for MIC and $0.031 \%$ for MBC. Conclusions: It was concluded that combining extracts of $2 \% F_{.} x$ ananassa and $2 \% O$. basilicum in various ratios were observably to have the antibacterial potential against S. sanguinis (ATCC 10556).
\end{abstract}

Keywords: Antibacterial activity; Strawberry; Fragaria x ananassa extract; Basil; Ocimum basilicum extract; Streptococcus sanguinis.

p-ISSN: 1979-0201; e-ISSN: 2549-6212; Available from: http://jurnal.unpad.ac.id/pjd/article/view/35894

DOI: 10.24198/pjd.vol33no1.35894

Submission: Sep 28, 2018; Accepted: Nov 16, 2021; Published online: Nov 31, 2021

*Corresponding author: Hendra Dian Adhita Dharsono, Department of Conservative Dentistry, Faculty of Dentistry Universitas Padjadjaran, Indonesia. Jalan Sekeloa Selatan I, Bandung, West Java, Indonesia, 40132. Phone: +62 815-6223343; E-mail: adhita@fkg.unpad.ac.id 


\section{INTRODUCTION}

Caries is a disease in the oral cavity that is multifactorial, infectious, chronic, and infectious, caused by the complex interaction between cariogenic bacteria of the oral cavity and fermented carbohydrates on the tooth surface over time which leads to demineralization of the hard tissues of the teeth. Dental caries are common and widely spread throughout the world population and are affecting the quality of life. It is caused by an imbalance of the normal flora of the oral cavity. Many studies have shown that although commensal microorganisms appear to support oral health and fight pathogens if they are not present in balance they are more pathogenic than commensal.

Streptococcus sanguinis is a Gram-positive bacterium, non-sporing, immobile, facultative anaerobic, commensal, and widely distributed in the oral cavity. S. sanguinis is known as a pioneer colony in the formation of dental plaque biofilms by assisting the attachment of other organisms in the biofilm. ${ }^{1,2,3}$ Based on data from National Institute of Health Research and Development (NIHRD). Indonesia Basic Health Research (RISKESDAS) 2018, the prevalence of dental caries in the Indonesian population is $53.2 \%$, which is approximately $93,998,727$ people. ${ }^{4}$ Plaque control is one of the caries prevention efforts that can be done mechanically by brushing teeth or with a combination of mouthwash. The basic ingredients contained in mouthwash consist of two types, namely chemical and herbal. Chemical mouthwashes generally contain active ingredients such as hydrogen peroxide, chlorhexidine, and alcohol. ${ }^{5}$

Beyond the proven efficacies of chemicalbased mouthwash in controlling plaque formation, drawbacks were also observed and being reported in previous studies. Chlorhexidine has been shown to be effective in controlling plaque formation, but it cannot be used in the long term because it contains alcohol, leaves an unpleasant taste on the tongue, and has side effects that can cause staining of teeth and restorations. ${ }^{5}$ Dry mouth, toxicity to oral connective tissue, and soreness of the mouth are some of other side effects caused by chemical-based mouthwash. Study reported the incidence of oral desquamations following the use of chemical-based mouthwash in children. ${ }^{3,6}$ Chemical-based side effect findings lead to searches for natural product potentials in dentistry as alternatives.

A review has discussed the efficacy of various herbal-based extracts and active compounds as a comparable antibacterial agent to chlorhexidine and sodium fluoride. Phytochemical properties of natural products are potential for their antibacterial and antioxidant activities, and being widely evaluated in the discovery of drugs. ${ }^{7}$ Natural products own a large range of chemical structures with uniques mechanism of actions that yields promising drug discoverings. 8,9

The advantages of plant-based are still compared to chemical products. Herbal mouthwashes are greatly in-demand due to their ability to fight oral pathogens and possesses fewer side effects compared to chemical products. . $10,11,12$ Herbal-based mouthwash can be obtained from vegetables and fruits, including strawberries and basil leaves. Strawberries (Fragaria $x$ ananassa) have been shown to have many nutrients, such as potassium, magnesium, phosphorus, calcium, iron, vitamins $A, E, K$, and $C$.

Several studies have shown that $F \cdot x$ ananassa contains flavonoid compounds that have antibacterial and antioxidant activities. $13,14,15$ Another active ingredient, xylitol, has been shown to prevent dental plaque formation, bacterial attachment, and inhibit enamel demineralization by reducing acid production. This plant has active compounds such as essential oils, alkaloids, saponins, flavonoids, triterpenoids, steroids, tannins, and phenols. ${ }^{16,17,18,19,20}$

Empirically, the potential of herbal products has been utilized as remedies for many ailments. It has been consumed in the form of a single extract or mixture of several herbal plants, but until now there is little information about the interaction of combinations between herbal ingredients.

The combination of two drugs can cause pharmacodynamics interactions, which is a phenomenon where the effect of one drug changes due to the presence of the other drug. The combination can provide synergistic or antagonistic effects. A synergistic effect is a goal that is pursued in the development of drug combinations in order to increase the efficacy and therapeutic effect of a drug..$^{21,22,23}$ 
A study by Chiedozie explained that the combination of herbal extracts which when used singly showed antibacterial and anti-inflammatory activities, will lead to synergistic properties and increase the activity better compared to a single usage. ${ }^{24}$ This study also revealed that herbalbased mouthwashes can replace chemical-based mouthwashes to maintain oral hygiene and prevent caries. ${ }^{24,25}$ The purpose of this study was to observe and determine the antibacterial potential of the combined extracts of $F . x$ ananassa and $O$. basilicum against $S$. sanguinis (ATCC 10556).

\section{METHODS}

This research was a descriptive study on antimicrobial activities of $F . x$ ananassa and $O$. basilicum) extract combinations on the growth of S. sanguinis ATCC 10556 by determining the Minimum Inhibitory Concentration (MIC) and Minimum Bactericidal Concentration (MBC) of the combination of the extract through a microdilution method.

Both plants have been identified by Plant Taxonomy Laboratory, Herbarium Jatinangor, Department of Biology, Faculty of Mathematics and Natural Science, Universitas Padjadjaran, Jatinangor, Sumedang as F. $x$ ananassa (Duchesne ex Weston) Duchesne ex RozierF and Ocimum basilicum $L$. The research was conducted at the Laboratory of Natural Products, Faculty of Mathematics and Natural Science, Universitas Padjadjaran, Jatinangor, Sumedang.

\section{Materials and Instruments}

F. $x$ ananassa was cultivated from Ciwidey District, Bandung Regency and O. basilicum was obtained from Cicalengka District, Bandung Regency, Indonesia in August 2018-Streptococcus sanguinis ATCC 10556 was prepared in Mueller Hinton Broth and Mueller Hinton Agar media for antibacterial test, and an anaerobic jar was used for the assay. Microdilution method for the antibacterial assay was using a 96-well microplate, micropipettes, microtubes, incubators, and Biochrom reader.

\section{Extraction of $F . x$ ananassa and 0 . basilicum}

Both samples of fresh F. $x$ ananassa and $O$. basilicum were individually cut into small pieces and extracted using a maceration method by immersing the samples in methanol solvent for 3 $\times 24$ hours at room temperature. The immersions were then filtered to obtain filtrates. These filtrates were evaporated using a rotary evaporator at a temperature of $40^{\circ} \mathrm{C}$ on low pressure to obtain concentrated methanol extracts of $F . x$ ananassa and $\mathrm{O}$. basilicum.

\section{Antibacterial assay of methanolic extracts $F . x$ ananassa and O.basilicum}

Antibacterial screening of methanolic extracts of $F . x$ ananassa and $O$. basilicum was initially observed for their inhibition zone using KirbyBauer disk diffusion in serial concentrations of $1 \%$, $2 \%, 3 \%, 4 \%$, and $5 \%$ against $S$. sanguinis. Bacteria solutions were prepared by growing 1 inoculating loops of bacteria in $5 \mathrm{~mL}$ broth medium, incubated for 24 hours at $37^{\circ} \mathrm{C}$. Following incubation, the turbidity of the solution was measured using a microplate reader at $620 \mathrm{~nm}$ and diluted to make a $0.5 \mathrm{Mc}$ Farland bacteria culture solution.

Later, $100 \mu \mathrm{L}$ of the culture solution was swabbed on the Muller Hinton agar medium, and $6 \mathrm{~mm}$ diameter paper discs containing $20 \mu \mathrm{L}$ samples were impregnated on the agar surface. Incubation of the samples was set for $48 \mathrm{~h}$ at $37^{\circ} \mathrm{C}$ and the whole process was repeated twice. Following the incubation, the inhibition zone was measured. The least concentrations of each sample that showed an inhibition zone was then set as the concentration to be used for the MIC and $M B C$ assay.

Combination of extracts with ratios of $1: 1$, $1: 2$, and $2: 1$ of active extract of $F . x$ ananass $a$ and $O$. basilicum were evaluated for their MIC and $M B C$ values. This antibacterial assay was using 96-well microplates. Pre-cultured bacteria were prepared in Mueller Hinton broth at $37^{\circ} \mathrm{C}$ under an anaerobic condition. Together with the extract combinations were then serially diluted two-fold at $37^{\circ} \mathrm{C}$ and incubated for $24 \mathrm{~h}$.

The turbidity was measured using a microplate reader at $620 \mathrm{~nm}$. Estimation of MIC value can be determined by the least concentration where the bacteria cells can be observed through the $\mathrm{OD}$ value and a confirmation procedure were done by swabbing the MIC in-well solution and incubated for 24 hours at $37^{\circ} \mathrm{C}$, whereas the $M B C$ 
is the least concentration that no bacteria growth observed through media colony counting.

\section{RESULTS}

To estimate the active antibacterial concentration of both $F . x$ ananassa and $O$. basilicum extracts, each of the samples with $1 \%, 2 \%, 3 \%, 4 \%$, and $5 \%$ concentrations were observed and measured for their inhibition zones against $S$. sanguinis (ATCC 10556). Methanol extract of F. $x$ ananassa showed an inhibition zone at a concentration of $2 \%$ (Table 1), while the antibacterial activity of methanol extract of $O$. basilicum was observed in a concentration of $2 \%$ as well (Tabel 1 ).

Table 1. Antibacterial screening of methanolic extract of $F . x$ ananassa and $O$. basilicum against $S$. sanguinis

\begin{tabular}{lccccc}
\hline & \multicolumn{5}{c}{ Inhibition Zones (mm) } \\
\cline { 2 - 6 } & $1 \%$ & $2 \%$ & $3 \%$ & $4 \%$ & $5 \%$ \\
\hline F. x ananassa & 0 & 7.8 & 8.6 & 9.4 & 11.4 \\
O. basilicum & 0 & 7.4 & 10.5 & 10.5 & 11.4 \\
\hline
\end{tabular}

Table 2. Data of MIC and MBC of Methanol extract of F. $x$ ananassa $2 \%$ and $O$. basilicum $2 \%$ against $S$. sanguinis

\begin{tabular}{lll}
\hline \multirow{2}{*}{ Extract } & \multicolumn{2}{c}{ Concentration (\%) } \\
\cline { 2 - 3 } & MIC & MBC \\
\hline F. x ananassa (2\%) & 0.125 & 0.25 \\
O. basilicum (2\%) & 0.312 & 0.63 \\
\hline
\end{tabular}

These concentrations of both samples were further used for determining MIC and MBC of each and the combination of the extracts.

The MIC for $2 \%$ F. $x$ ananassa was $0.125 \%$. This is confirmed by the turbidity value read at a concentration of $0.125 \%$, and further readings showed that no bacteria growth at a concentration of $0.25 \%$. Therefore, the $M B C$ of $2 \%$ extract of $F$. $x$ ananassa against $S$. sanguinis is $0.25 \%$ (Table 2 ). For the extract of $O$. basilicum, the readings showed that the MIC is $0.031 \%$, and the $M B C$ is at a concentration of $0.63 \%$. Each of the extracts were

Table 3. Data of MIC and MBC of F. $x$ ananassa to 0 . basilicum extract combinations ratio (vol:vol) against $S$. sanguinis

\begin{tabular}{ccc}
\hline \multirow{2}{*}{ Ratio } & \multicolumn{2}{c}{ Concentration (\%) } \\
\cline { 2 - 3 } & MIC & MBC \\
\hline $1: 1$ & 0.0156 & 0.0312 \\
$1: 2$ & 0.0156 & 0.0312 \\
$2: 1$ & 0.0156 & 0.0312 \\
\hline
\end{tabular}

then combined with ratios (volume to volume) of $1: 1,1: 2$, and $2: 1$, and each combination was tested for its MIC and MBC. Referring to Table 3, all volume to volume ratios of $F . x$ ananassa to O. basilicum extract combinations tested $(1: 1$, $1: 2,2: 1)$ showed similar values for their MICs and MBCs. The MICs were $0.0156 \%$ and the MBCs were 0.0312\% (Table 3).

\section{DISCUSSION}

The minimum concentration for $F . x$ ananass $a$ and O. basilicum to inhibit $S$. sanguinis were $2 \%$ for both the extracts. Even though the inhibition zone diameters were slightly observed visually, indeed, they have shown the antibacterial activities and were confirmed with the lower concentration (1\%) that did not show any inhibition zone. This finding was proven to have a contradictory result with the study on $O$. basilicum conducted by Anggriani et al. ${ }^{26}$ that stated the minimum inhibitory zone is at $5,000 \mathrm{ppm}$ which is equal to $0.5 \%$. Meanwhile, the result was found to be similar with the study conducted by Rikmasari et al. ${ }^{27}$ Similar result for strawberry sensitivity test were also contradictory, Phillip et $a^{28}$ definitely stated that despite their high polyphenol content, strawberry did not show any antibacterial activity.

The studies mentioned previously were using similar method, however, the current study had different result. This phenomenon would probably be due to the purity and sensibility of the bacteria used. Impurity and prolonged storing time of bacteria, will alter bacteria properties, whereas source of the natural products will yield result inconsistencies as well. ${ }^{29}$ Furthermore, as the concentration increased, the inhibition zone appeared to correlate linearly. Therefore, the concentration of $2 \%$ of the samples was estimated as the least concentration owing to the antibacterial effect of S. sanguinis, and is further used in the study.

The MIC and MBC values for the combination of $F . x$ ananassa and $O$. basilicum extracts with a ratio of $1: 1,1: 2$, and $2: 1$ against $S$. sanguinis were shown to be lower than the MIC values and MBC each extract of $F . x$ ananassa and $O$. basilicum respectively, MIC $0,125 \%$ and $0.016 \%$ with an MBC value of $0,25 \%$ and $0.031 \%$. The ratio variations 
for the combination of the two single extracts did not perform any different towards $S$. sanguinis and gave the same MIC and MBC values. This phenomenon could be due to the relatively wide concentration ratio being tested that results in the same values. It also showed that the combination of the two single extracts could reduce MIC and MBC against $S$. sanguinis bacteria (ATCC 10556).

Previous data on the combination of $F . x$ ananassa and 0 . basilicum were not available, thus this result can give a new perspective on the combinations studied in this research. In general, the effects that arise from an herbal ingredient, especially herbal ingredients that are combined are often unpredictable. Che et al. ${ }^{24}$ stated, when herbal ingredients are used in combination, interactions can occur between the components contained in each ingredient. The most desirable interactions are those that can yield additional therapeutic benefits. ${ }^{30,31}$

A combination of $F . x$ ananassa and $O$. basilicum extracts which both had antibacterial activity against $S$. sanguinis show lower MIC and MBC compared to the MICs and MBCs of each of the extracts. Pharmacological activity of a single herbal ingredient can prolong the effect, increase potency, and/or reduce the reverse effect to be synergistic or antagonistic when combined with other herbal ingredients. In this study, the combination of the two single extracts showed synergistic results. A condition is said to be synergistic when the combination of two antimicrobial agents produces an antibacterial effect that is greater than the power shown by the individual components. $22,24,25,30,31$

A synergistic effect can be achieved if the added extract affects other targets or its components interact with each other to increase solubility thereby increasing the antibacterial activity of one or more compounds of the main extract. $22,24,25,30,31$ This synergistic effect is related to the active substance contained in every single compound which when combined will increase the effectiveness of the active substance compared if works alone. F. $x$ ananassa and $O$. basilicum both had been phytochemically screened for their phenolic compounds, flavonoids, and tannins. This active substance has antiseptic and antibacterial effects that work by damaging the bacterial cell membrane as well as being an antioxidant. 15, 16, 19,22,30
Alkaloid, polyphenol, flavonoids, tannins, and quinon derived from $F . x$ ananass $a$ and terpenes and caffeic acid of $O$. basilicum play role in effective antibacterial activity against $S$. sanguinis. ${ }^{5,32} \mathrm{This}$ study combines the extracts of $F . x$ ananassa and $O$. basilicum, a combination that is expected to increase the therapeutic effect and can be developed as a potential and more effective mouthwash against S.sanguinis.

\section{CONCLUSION}

The combined extracts of $F . x$ ananassa $2 \%$ and $O$. basilicum in were observably have the antibacterial potential against S. sanguinis (ATCC 10556).

\section{ACKNOWLEDGMENT}

This study was funded through Universitas Padjadjaran Institutional Grant "Riset Kompetensi Dosen Unpad” (2017-2018).

\section{REFERENCES}

1. Heymann HO, Swift Jr. EJ, Ritter AV. Sturdevant's Art and Science of Operative Dentistry. $6^{\text {th }}$ ed. St. Louis: Mosby Elsevier; 2013. p. 41-3.

2. Zhu B, Macleod LC, Kitten T, Xu P. Streptococcus sanguinis biofilm formation \& interaction with oral pathogens. Future Microbiol. 2018 Jun 1;13(8):915-932. DOI: $10.2217 / \mathrm{fmb}-2018-0043$

3. Fani M, Kohanteb J. Inhibitory activity of Aloe vera gel on some clinically isolated cariogenic and periodontopathic bacteria. J Oral Sci. 2012 Mar;54(1):15-21. DOI: 10.2334/josnusd.54.15

4. National Institute of Health Research and Development (NIHRD). Indonesia Basic Health Research (RISKESDAS) 2018. Jakarta: Ministry of Health of the Republic of Indonesia; 2018. p. 110-9.

5. Singh $P$, Kaur $M$, Singh I. Efficacy of chlorhexidine vs herbal mouthwash mouth wash in college students: A comparative study. Int J of Med and Health Res. 2017;3 (5):78-81.

6. Jeon JG, Rosalen PL, Falsetta ML, Koo H. Natural products in caries research: current (limited) knowledge, challenges and future perspective. Caries Res. 2011; 45(3): 243-63. 
DOI: $10.1159 / 000327250$

7. Megalaa N, Kayalvizhi G, Silas AJ, Sajeev R, Saravana Kumar MS. Role of herbal leaf extracts in caries prevention. Int $\mathrm{J}$ Cont Med Res. 2014; 1(2): 71-8

8. Yuan H, Ma Q, Ye L, Piao G. The traditional medicine and modern medicine from natural products. Molecules. 2016 Apr 29;21(5):559. DOI: $10.3390 /$ molecules21050559

9. Harvey AL, Edrada-Ebel R, Quinn RJ. The re-emergence of natural products for drug discovery in the genomics era. Nat Rev Drug Discov. 2015 Feb;14(2):111-29. DOI: 10.1038/ $\underline{\mathrm{nrd} 4510}$

10. Siddeshappa ST, Bhatnagar S, Yeltiwar RK, Parvez H, Singh A, Banchhor S. Comparative evaluation of antiplaque and antigingivitis effects of an herbal and chlorine dioxide mouthwashes: A clinico microbiological study. Indian J Dent Res. 2018 Jan-Feb;29(1):34-40. DOI: $10.4103 /$ ijdr.IJDR 39116

11. Jangid K, Doraiswamy JN, Saji VS, dan Malaiappan S. Efficacy of herbal mouthwashes compared to chlorhexidine in gingivitisa systematic review. Int $J$ of Ethnobiol \& Ethnomed. 2014; 1(1): 1-12

12. James $P$, Worthington HV, Parnell $C$, Harding $M$, Lamont T, Cheung A, Whelton H, Riley P. Chlorhexidine mouthrinse as an adjunctive treatment for gingival health. Cochrane Database Syst Rev. 2017; 3(3): CD008676. DOI: 10.1002/14651858.CD008676.pub2

13. Sitorus TE, Purwaningsih S, Wahyunitisari MR. Antibacterial effect of strawberry (Fragaria $x$ ananassa) extract on pathogenic serotype 1-11 Escherichia Coli revealed using dilution method. Fol Med Indo. 2012; 48(4): 167-73.

14. Islam MS, Riaz Z, Waqa A, Nassar M, Hossain A, Rahman MM. The effect of cranberry, Strawberry and blueberry juices on the viability of cariogenic bacteria: an in vitro study. Journal of International Dental \& Medicinal Research. 2020; 13(2): 436-41

15. Widyarman AS, Widjaja SB, Idrus E. 2017. Strawberry extract's effects on Enterococcus faecalis and Porphyromonas gingivalis biofilms in vitro. Sci Dentl J. 2017; 1(1): 1-5. DOI: 10.26912/sdj.v1i1.1911

16. Rezzoug M, Bakchiche B, Gherib A, Roberta A, FlaminiGuido, Kilinçarslan Ö, Mammadov
R, Bardaweel SK. Chemical composition and bioactivity of essential oils and Ethanolic extracts of Ocimum basilicum L. and Thymus algeriensis Boiss. \& Reut. from the Algerian Saharan Atlas. BMC Complement Altern Med. 2019; 19(1): 146. DOI: 10.1186/s12906-0192556-y.

17. Astuti P, Saifullah TN, Wulanjati MP, Yosephine $A D$, Ardianti D. Basil essential oil (Ocimum basilicum L.) activities on Streptococcus mutans Growth, biofilm formation and degradation and its stability in micro-emulsion mouthwash formula. Int $\mathrm{J}$ of Pharm and Clin Res. 2016; 8(1): 26-32.

18. Yosephine $A D$, Wulanjati MP, Saifullah $T N$, Astuti P. Mouthwash formulation of basil oil (Ocimum basilicum $L$ ) and in vitro antibacterial and antibiofilm against Streptococcus mutans. Trad Med J. 2013; 18(2): 95-102. DOI: 10.22146/tradmedj.8036

19. Lahiri D, Nag M, Dutta B, Dey S, Mukherjee D, Joshi SJ, Ray RR. Antibiofilm and anti-quorum sensing activities of eugenol and linalool from Ocimum tenuiflorum against Pseudomonas aeruginosa biofilm. J Appl Microbiol. 2021 Jun 2. DOI: $10.1111 / \mathrm{jam} .15171$

20. Melo RS, Albuquerque Azevedo ÁM, Gomes Pereira AM, Rocha RR, et al. Chemical composition and antimicrobial effectiveness of Ocimum gratissimum L. essential oil against multidrug-resistant isolates of Staphylococcus aureus and Escherichia coli. Molecules. 2019; 24(21): 3864. DOI: $10.3390 /$ molecules24213864

21. Walker R dan Whittlesea C. Clinical Pharmacy and Therapeutics $5^{\text {th }}$ Ed. Edinburgh: Churchill Livingston Elsevier; 2012.p. 57

22. Yin N, Ma W, Pei J, Ouyang Q, Tang C, Lai L. Synergistic and antagonistic drug combinations depend on network topology. PLoS One. 2014; 9(4): e93960. DOI: 10.1371/journal. pone. 0093960

23. C Che CT, Wang ZJ, Chow MS, Lam CW. Herbherb combination for therapeutic enhancement and advancement: theory, practice and future perspectives. Molecules. 2013; 18(5): 512541. DOI: $10.3390 /$ molecules 18055125

24. Chiedozie EI, Ahamefule OF, dan Ukamaka AA. Anti-Inflammatory, Antimicrobial and Stability Studies of Poly-Herbal Mouthwashes against 
Streptococcus mutans. J of Pharm and Phyt. 2016; 5(5): 354-61.

25. Chouhan S, Sharma K, Guleria S. Antimicrobial Activity of Some Essential Oils-Present Status and Future Perspectives. Medicines (Basel). 2017; 4(3): 58. DOI: 10.3390/ medicines 4030058

26. Anggraini F, Satari MH, Mariam MS. Bacterial inhibition test of methanolic extracts of strawberry (Fragraia $x$ ananassa Duchesne), lime (Citrus aurantifolia), and radish (Raphanus sativus L.), towards Streptococcus sanguis ATCC 10556 .Padjadjaran J Dent. 2018; 30(2): 98-102.

27. Rikmasari R, Zubaedah C, Dharsono HDA, Satari MH, Herdiyati Y, Kurnia D. Antibacterial potential of kemangi (ocimum basilicum l.) Against pathogenic oral bacteria: An in vitro Study. Res J Medic Plants 2020; 14: 8-14. DOI: 10.3923/rjmp.2020.8.14

28. Philip N, Leishman S, Bandara H, Walsh L. Growth inhibitory effects of antimicrobial natural products against cariogenic and health-associated oral bacterial species. Oral Health Prev Dent. 2020; 18(1): 537-42. DOI: 10.3290/j.ohpd.a44307

29. Pinevich AV, Andronov EE, Pershina EV, Pinevich AA, Dmitrieva HY. Testing culture purity in prokaryotes: criteria and challenges. Antonie Van Leeuwenhoek. 2018 Sep;111(9):1509-21. DOI: $10.3390 /$ microorganisms 8060936

30. Nidhi S. Concept of Drug Interaction. International Res J Pharmacy. 2012; 3(7): 120-2.

31. Tekin E, Beppler C, White C, Mao Z, Savage VM, Yeh PJ. Enhanced identification of synergistic and antagonistic emergent interactions among three or more drugs. J R Soc Interface. 2016 Jun;13(119):20160332. DOI: 10.1098/ rsif.2016.0332

32. Bilal A, Jahan N, Ahmed A, Bilal SN, Habib S, Hajra S. Phytochemical an pharmacological studies on Oncimum basilicum Linn- a review. Int J Curr Res Rev. 2012; 4(23): 13-83.DOI: $\underline{10.31782 / 2231-2196}$ 